\title{
ERRATUM
}

To the paper

\section{Physico-chemical forms of radiostrontium in simulated freshwaters}

\author{
T. Kekki," R. J. Rosenberg,* T. Jaakkola***
}

* Technical Research Centre of Finland, VIT Chemical Technology, P. O. Box 1404, FIN-02044 Espoo, Finland

** University of Helsinki, Department of Chemistry, Laboratory of Radiochemistry, P. O. Box 55, FIN-00014 University of Helsinki, Finland

appeared in the Journal of Radioanalytical and Nuclear Chemistry, Vol. 224, Nos 1-2, October (1997) 77-81. On page 79, in the first column, row No. 7, the correct sentence is as follows: Then the water sample was fractionated as shown in Fig. 1. 